\title{
Technologization of student behavior management in the modern system of secondary vocational education
}

\author{
Darya Kirillovna Smolyakova
}

Sevastopol College of Service and Trade, Oktyabrskoy Revolyutsii Avenue, 89, 299038 Sevastopol, Russian Federation

\begin{abstract}
The article studies the theoretical foundations of technologization of student behavior management in the modern system of secondary vocational education (SVE). The author systematizes scientific approaches to the study of technologization of human behavior management in the modern system of vocational education. Concepts such as "social behavior in a technologized society", "technologization of student behavior management" and "educational behavior" have been elaborated and introduced into the conceptual apparatus of management sociology. The effectiveness of the educational process has been substantiated to primarily lie in the expansion of knowledge and the acquisition of the ability by students to apply it in new transformational situations, rather than depend on the simple assimilation of certain volumes of knowledge by students. Social technologization presupposes a convincing vision of the transformation of the educational program and a vision of modern education in the era of digitalization. The article presents the model of the process of social technologization and provides the classification of social technologies of management. The trends in the development and implementation of innovative social technologies for managing human behavior in modern educational institutions are identified and summarized.
\end{abstract}

\section{Introduction}

The actualization of the theoretical understanding and the practical significance of the managerial aspects of the behavioral component of a person and social groups in society is associated with a decrease in the importance of self-determination, self-organization, and personal status of a person caused by technologization that began in industrial society. The formation of a new mass consciousness took place in an industrial society within the framework of simplification, standardization, and massification of behavior. These processes acted as the effect of technologization, simplifying the modeling of the situational behavior of an individual and entire social groups. However, sociological science considers the issue of the foundations, mechanisms, trends and prospects for the development of society as one of the most important, interesting, and at the same time difficult to understand the behavioral component of a person.

Managing human behavior includes the formation and development of certain norms, motivational attitudes of a person, change and systematic correction of behavior patterns that 
are formed in accordance with long-term development and the accepted system of values. The practical result of this modification will be an effective model of the individual's preferred behavior.

I.V. Blauberg and V.I. Bogoliubov, V.V. Guzeeva, V.I. Zagviazinskii, M.V. Klarin, G.B. Kornetov, Iu.S. Manuilov, V.L. Nazarov, T.A. Pankova, O.Iu. Strelov, E.G. Iudin and others have studied the technological approach to education. In foreign science, the initial concepts of human behavior were developed by M. Weber, F. Znanetsky, R. MacGyver, G. Becker, V. Pareto, T. Parsons, J. Habermas. The use of modern technologies in the educational sphere was studied by N.V. Bordovskaia, M.Iu. Bukharkina, I.B. Gotskaia, T.A. Dmitrenko, V.S. Idiatulin, M.A. Karmanova, E.B. Kurkin, M.M. Levin, N.A. Moreva, T.N. Noskova, A.P. Panfilova, E.S. Polat, I.V. Robert, Iu.G. Fokin, M.V. Tsiulina, E.I. Chernysheva and others.

However, the problem of technologization of student behavior management in the modern system of secondary vocational education (SVE) was not a special subject of research, which requires further scientific study to resolve the contradictions between the set of educational services provided and the requirements for the quality and content of secondary vocational education in the labor market.

The methodological basis of the research was sociological concepts of social behavior (M. Weber, F. Znanetskaia, R. MacGyver, G. Becker, V. Pareto, T. Parsons, J. Habermas, etc.); foreign teaching concepts as an extension of the student's personal social experience (T. Brameld, A. Maslow, K. Rogers); ideas of the educational system from the perspective of humanism (A.B. Gavrilin, V.A. Karakovsky, A.T. Kurakin, L.I. Novikova, N.L. Selivanova, etc.); technological approach in education (V.P. Bespalko, V.I. Bogoliubova, V.V. Guzeeva, M.V. Klarin, V.M. Monakhova and G.K. Selevko, etc.). To study the technologization of student behavior management in the modern system of secondary vocational education (SVE), we applied institutional (E. Durkheim, J. Dewey, etc.), structural-functional (M. Granovetter, P. DiMaggio, W. Powell, etc.) and activity (M. Archer, T. Burns, E. Giddens, P. Shtompka, etc.) approaches. The general scientific methods of cognition used were historical method, analysis and synthesis, and generalization.

\section{Results and Discussion}

The problem of technologization of student behavior management in the modern system of secondary vocational education (SVE) is the subject of study by sociologists, philosophers, historians, psychologists, and teachers. A review of the available research on this topic has revealed several aspects of its study.

From M. Weber's position, any human behavior in society is based on a certain action, which acts as "... the simplest behavioral unit, which is associated with the acting individual with the subjective meaning" [3, p.503]. The scientist defines social action as "...the action of one person, directed at another" [3, p. 345]. T. Parsons developed similar ideas, arguing that "...all social practice, in essence, is a set of relationships between people performing their duties" [13, p. 239]. Later, A. Touraine introduced the concept of "social subject" into the theory of social action, that is, "... at the societal level, it understands social movements" [16, p. 134]. In turn, P.L. Berger states no contradiction between the objective determinism of E. Durkheim's social activity and the subjective motivation of M. Weber's social activity. Only that both of these phenomena exist simultaneously, conditioning and explaining that "...society defines us, and we, in turn, define society" [2, p. 82]. As a result, J. Alexander confirms the above: “...social action is determined by three main components, namely culture, individuality, and social system" [1, p. 216].

Having reviewed the huge database of foreign scientific sources on this issue, we can state that most of them consider social behavior as "...a set of human behavioral processes associated with the satisfaction of physical and social needs, identified in the form of a 
reaction to the surrounding social environment. The subject of social behavior can be an individual person or a social group".

In this context, the model of congruence of organizational behavior by J. Nadler seems interesting, according to which "...management of changes in an organization is the coordination of all the constituent parts of the system, which is the organization itself. In this case, it is necessary to coordinate the input, internal, and output parts of the system. Input elements come from the external environment of the organization and include requirements and opportunities, all kinds of resources (human, financial, informational, etc.), the history of the organization's development, as well as its strategy (the vision and mission of the organization, formulated in the context of its history and considering available resources and opportunities)" [11, p. 164].

Thus, as a result of the generalization of scientific works, we can summarize that social behavior is understood as the forms and methods of manifestation of preferences and attitudes both by an individual and a social group, as well as opportunities and skills for social action or interaction in close relationship with socially significant objects under technologization.

In this regard, social technologies, being a necessary element in the processes of social management, act as a means of a kind of translation of socio-cultural norms into the language of social management practice, the implementation of specific decisions that guide people to achieve their goals. Therefore, an analysis of modern trends in the development of social technologization shows a shift in emphasis towards the management of public relations, confirmed by the research by V.L. Glazychev [5], V.D. Simonenko [14], and R.G. Smirnov [15].

Summarizing scientific and methodological research, the process of social technologization can be schematically represented as a model in Fig. 1.

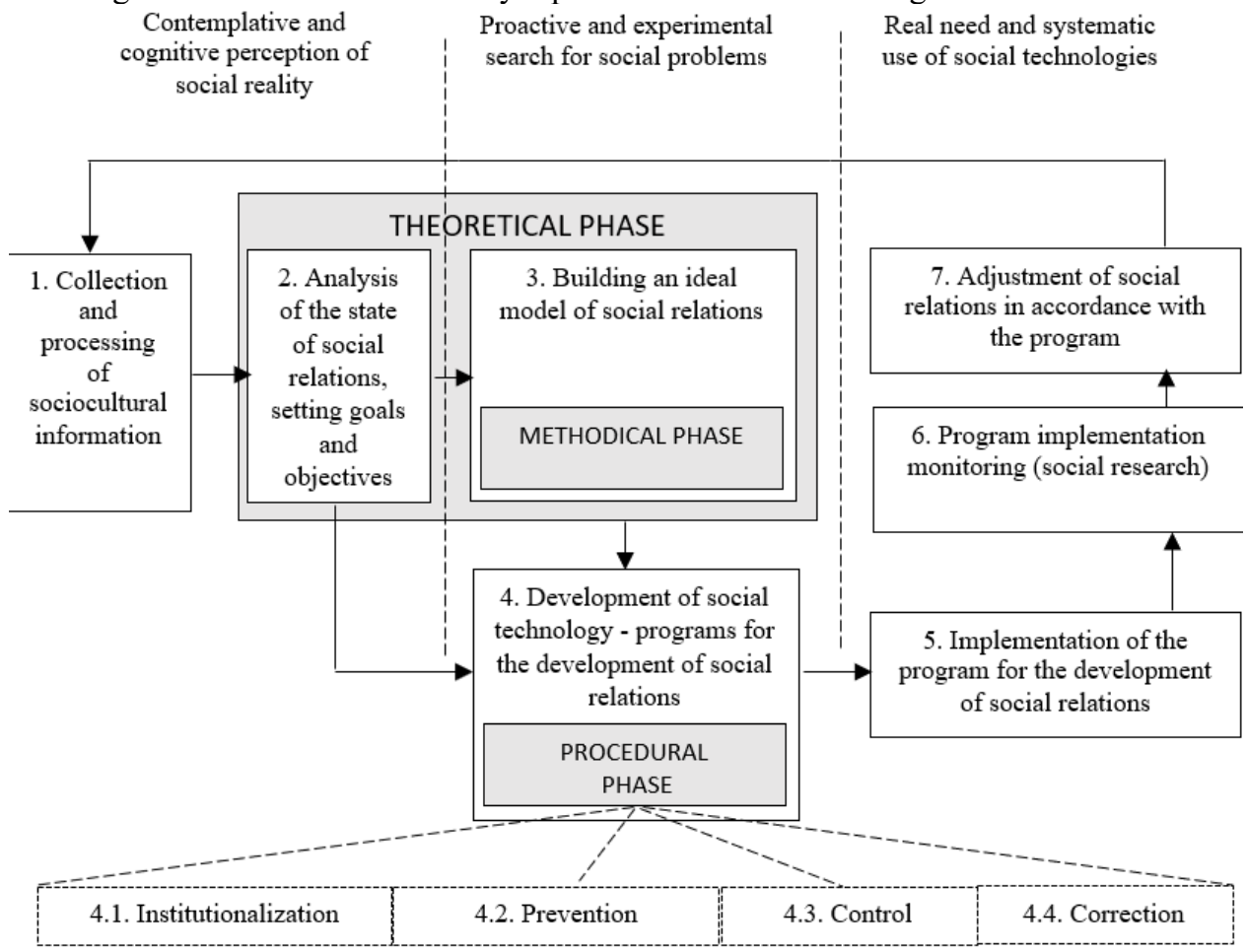

Fig. 1. Social technologization model (compiled by the author according to $[7,8]$ ) 
In the context of constant global changes under the influence of a new technological cycle, driven by flexibility and innovation, awareness of the need for modern educational transformations both at the level of secondary vocational education institutions and the education system as a whole becomes more obvious in the process of social technologization.

The effectiveness of the educational process has been substantiated to primarily lie in the expansion of knowledge and the acquisition of the ability by students to apply it in new transformational situations, rather than depend on the simple assimilation of certain volumes of knowledge by students. That is "...the world no longer encourages people to learn, as search engines know everything. it is important how they use this knowledge, how they behave in and adapt to the world" [9, p. 139]. In other words, the essence of the technologized educational process in today's conditions lies in the formation and development of students' creative abilities, critical thinking, the ability to communicate and cooperate; the relevance of knowledge, understanding and ability to use the potential of new technologies; and, finally, and no less important, in personal features, thanks to which there is a person's self-fulfillment for the sustainable development of all mankind. “...Today, curiosity, openness to new things and the creation of connections between ideas that previously seemed unrelated to each other are important, which, in turn, requires having an idea of different areas of knowledge, not just one, and being receptive to new information" [6, p. 25].

Therefore, modern research in management technologies (as a result of understanding the processes of management sociologization, approval of a systematic approach to management) is actively pursuing both the development of new social technologies and the analysis of the features of technologization of student behavior management (Fig. 2).

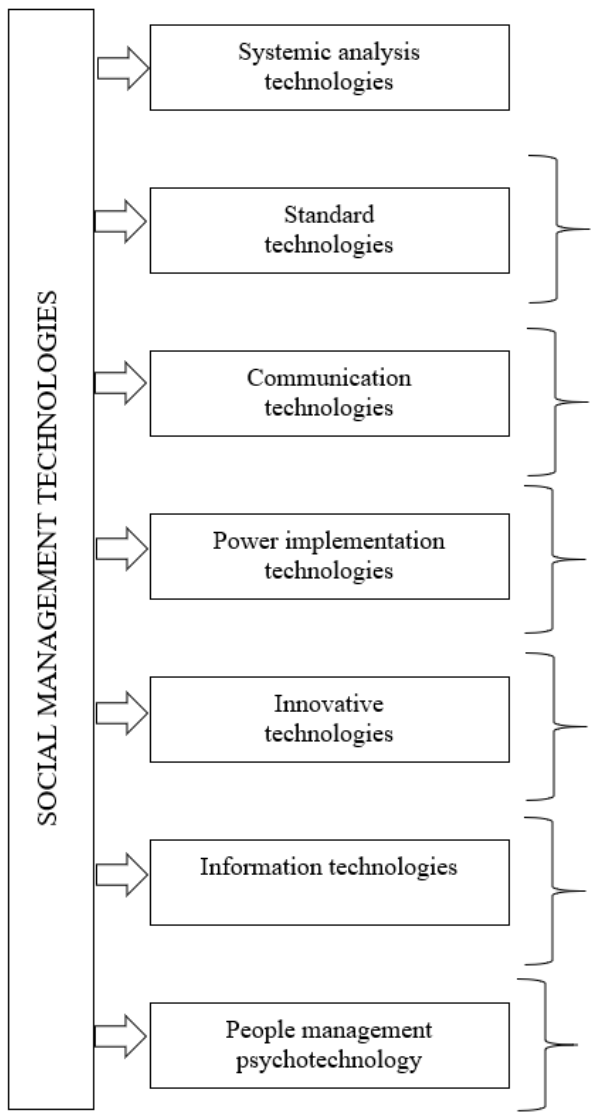

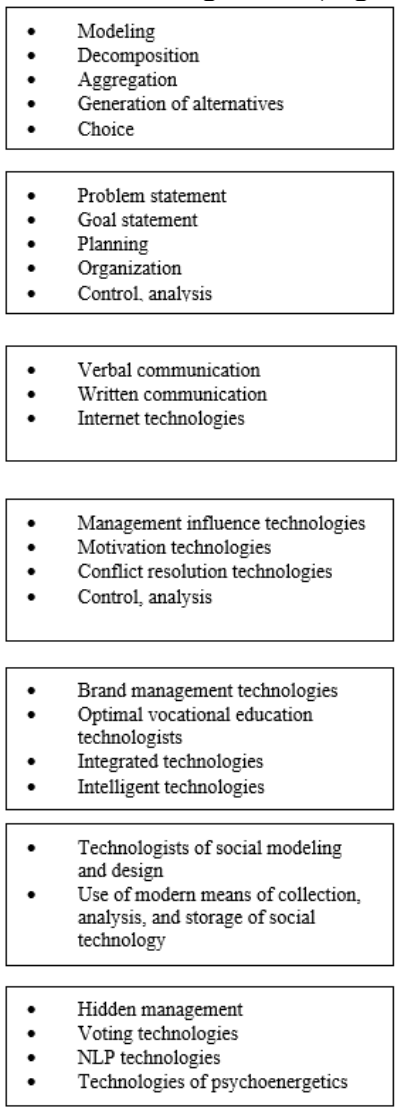

Fig. 2. Classification of social management technologies (compiled by the author according to [10]) 
In secondary vocational education institutions, innovative systems of education and training imply the ability of self-management, which implies the orderliness of didactic and educational processes and their relationship with upbringing. On this basis, these systems must be considered as a whole.

Most scientists try to make innovative changes through the forms and methods of teaching, in some cases not yet widely used in pedagogy. For example, scientists from Voronezh State University S.A. Volkova and T.A. Volkova consider the role of innovative methods in the knowledge economy. After analyzing general trends in the development of the educational process, innovative approaches are reduced to three forms that are relatively new for pedagogy in general and pedagogy of higher education and private methods: analysis of educational situations, problem-based learning and teaching in small groups. The article also names methods of distance support for online student learning, the use of multimedia tools, and interactive testing systems. The authors attribute all this to the so-called knowledge economy, leaving the essence of this concept unrevealed [4].

V.Z. Panina in her publication refers methodological and theoretical issues of the introduction of innovative activities directly to the technology of advanced learning in an educational institution. V.Z. Panina operates in this analysis with three relatively new concepts - "innovation dynamics" (the sequence of transforming knowledge into technical or social reality), "innovative thinking" (the ability of a teacher and higher education to develop mechanisms and methods of its formation) and "self-management" (active motivation of the student in learning, reflected in the educational process of the full cycle of professional activity) [12].

J.L. Tsaurkubule in her works describes the conditions favorable to introduce innovations: a) creating a competitive atmosphere; b) the professional growth of the teacher, his/her creative search; c) the use of new methods and means of information transmission; d) optimization of the educational process (in this case, innovative changes should be large enough to radically change the course of the educational process); e) the introduction of innovations at the expense of the reserves of the educational institution itself; f) reliance on the newly developed philosophical foundations of education; g) a qualitative change in the personality of the student [18].

At the same time, such a consideration of innovations does not always lead to restructuring in the educational process, as only certain methods and techniques are introduced that do not give the proper coloring to its deep innovative restructuring in modern educational organizations.

E.L. Fedotova presents a more ordered view of the problem by considering a fairly organic connection between innovative methods and the educational process. She has revealed some patterns in the analysis of the theory and practice of the educational process, such as a) an increase in the innovative component in the content and methods of teaching; b) acceleration of the aging process of knowledge and, accordingly, the fundamentalization of education, leading to its dynamic renewal; and c) transition from private innovation models to integrated cluster innovations. In her works she briefly characterizes three teaching methods, differing in the level of their innovativeness: passive, active, and interactive [17].

Arguing with the authors of many publications, nevertheless, pedagogical innovation can be described as a broader and deeper innovation that drastically changes the educational process.

The introduction of innovative technologies into the educational process of institutions of secondary vocational education (SVE) presupposes a certain reorganization of the processes of training and education. The main task of the educational process is already understood as "teaching to learn", while the student is no longer an object but a subject of learning. The modern labor market poses more stringent requirements for professional knowledge and skills, as well as the competencies of future graduates of SVE institutions. 
The innovativeness and technologization of the educational process affect such areas of training as the development of the content of educational standards of a new generation, the development and implementation of new social learning technologies and new methods of studying innovative training programs, changing the form of activity and style of thinking of teachers and students, the creation and development of creative teams, communities and others. In a generalized form, important events in the development of educational technologies, published in 2012-2019, are presented in Table 1.

Table 1. Important developments and achievements in educational technologies in the system of secondary vocational education [19]

\begin{tabular}{|c|l|l|l|l|l|l|l|l|}
\hline Educational technologies & 2012 & 2013 & 2014 & 2015 & 2016 & 2017 & 2018 & 2019 \\
\hline Tablet computers & & & & & & & & \\
\hline Natural user interfaces & & & & & & & & \\
\hline Mobile education & & & & & & & & \\
\hline Internet of things & & & & & & & & \\
\hline Games and gamification & & & & & & & & \\
\hline Analytical technologies & & & & & & & & \\
\hline 3D printing & & & & & & & & \\
\hline $\begin{array}{c}\text { MOOC (massive open online } \\
\text { courses) }\end{array}$ & & & & & & & & \\
\hline Next-generation LMS & & & & & & & & \\
\hline Blockchain & & & & & & & & \\
\hline $\begin{array}{c}\text { Adaptive learning } \\
\text { technologies }\end{array}$ & & & & & & & & \\
\hline Bring your gadget with you & & & & & & & & \\
\hline Makerspace & & & & & & & & \\
\hline Blended learning & & & & & & & & \\
\hline Virtual assistants & & & & & & & & \\
\hline Wearable technology & & & & & & & & \\
\hline Robotics & & & & & & & & \\
\hline Mixed reality & & & & & & & & \\
\hline Artificial intelligence & & & & & & & \\
\hline
\end{tabular}

Key trends contributing to the introduction of new technologies in SVE institutions are shown in Table 2.

Table 2. Key trends contributing to the introduction of new technologies in SVE institutions [19]

\begin{tabular}{|c|c|c|c|}
\hline $\begin{array}{c}\text { Year of } \\
\text { publication }\end{array}$ & Short-term outlook & Mid-term outlook & Long-term outlook \\
\hline \multirow[t]{2}{*}{2015} & $\begin{array}{l}\text { Increased use of blended } \\
\text { learning }\end{array}$ & $\begin{array}{l}\text { More attention to the } \\
\text { assessment of educational } \\
\text { resources }\end{array}$ & $\begin{array}{c}\text { Promotion of a culture of } \\
\text { transformation and } \\
\text { innovation }\end{array}$ \\
\hline & Redesign of classrooms & $\begin{array}{c}\text { Spreading of open } \\
\text { educational resources }\end{array}$ & $\begin{array}{c}\text { Intensification of inter- } \\
\text { institutional collaboration }\end{array}$ \\
\hline \multirow[t]{2}{*}{2016} & $\begin{array}{l}\text { More attention to the } \\
\text { assessment of } \\
\text { educational resources }\end{array}$ & Redesign of classrooms & $\begin{array}{c}\text { Promotion of a culture of } \\
\text { transformation and } \\
\text { innovation }\end{array}$ \\
\hline & $\begin{array}{c}\text { Increased use of blended } \\
\text { learning }\end{array}$ & $\begin{array}{l}\text { Transition to advanced } \\
\text { teaching methods }\end{array}$ & $\begin{array}{l}\text { Rethinking of the } \\
\text { institutions' operation }\end{array}$ \\
\hline \multirow[t]{2}{*}{2017} & $\begin{array}{l}\text { Models of blended } \\
\text { learning }\end{array}$ & $\begin{array}{l}\text { More attention to the } \\
\text { assessment of the } \\
\text { educational process }\end{array}$ & $\begin{array}{c}\text { Promotion of a culture of } \\
\text { transformation and } \\
\text { innovation }\end{array}$ \\
\hline & Coeducation & Redesign of classrooms & $\begin{array}{l}\text { Advanced learning } \\
\text { approaches }\end{array}$ \\
\hline 2018 & $\begin{array}{l}\text { Growing interest in } \\
\text { measuring learning }\end{array}$ & $\begin{array}{l}\text { Spreading of open } \\
\text { educational resources }\end{array}$ & $\begin{array}{l}\text { Development of innovative } \\
\text { innovations }\end{array}$ \\
\hline 2019 & Redesign of classrooms & $\begin{array}{c}\text { The emergence of new forms } \\
\text { of interdisciplinary research } \\
\text { bases }\end{array}$ & $\begin{array}{c}\text { Interdepartmental and } \\
\text { intersectoral collaboration }\end{array}$ \\
\hline
\end{tabular}


Considering the above data, we can state with confidence that the key trends contributing to the introduction of new technologies in SVE institutions have a direct impact on the policy, management and practical results of the educational process. The fundamental resulting factor of such technological trends is a qualitative change in the qualification competencies and skills of teachers with less loss of time for the presentation of training courses due to the modification and technologization of academic subjects and material resources, and who in this situation should have extensive knowledge and skills, project thinking, the ability to organize and oversee the learning process and act as a "personal advisor".

\section{Conclusion}

1. A constantly changing global environment brings it forth under the influence of a new technological cycle and digitalization that, in secondary vocational education institutions, innovative systems of education and training imply the ability of selfmanagement, which implies the orderliness of didactic and educational processes and their relationship with upbringing and form a single whole.

2. An awareness of the need for modern educational transformations both at the level of secondary vocational education institutions and the education system as a whole becomes more obvious in the process of social technologization.

3. Technology in this aspect is built on the foundation of generalized concepts personality-oriented, problem-oriented, individual-typological, etc., where learning is an integrative set (and even a system) of selected innovative forms, methods, and techniques.

\section{References}

1. J. Alexander, The meanings of social life: cultural sociology (2013)

2. P.L. Burr, An invitation to sociology: a humanist perspective (1996)

3. M. Weber, Selected works (1990)

4. S.A. Volkova, T.A. Volkova, Econominfo, 24, 67(2015)

5. V.L. Glazychev, Technology and technologization, http://www.shkp.ru/

6. M.S. Guseltseva, Cultural-analytical approach to the study of the evolution of psychological knowledge (2015)

7. L.Ia. Diatchenko, Higher education in Russia, 9, 47 (2009)

8. Iu.V. Karavaeva, Theory and practice of social development, 24, 96 (2015)

9. P.I. Kasatkin, Value axiomatics of educational space (2018)

10. E.N. Kniazeva, Fostering social innovation is creative management. Synergetics and forecasting, http://spkurdyumov.ru

11. J. Nadler, S. Khibino, J. Farrell, Full-spectrum thinking (2001)

12. V.Z. Panin, Bulletin of Kazan Technological University, 16, 316 (2014)

13. T. Parsons, On the structure of social action (2002)

14. V.D. Symonenko, Technologization and innovativeness of education as a strategic factor of industrial growth in market conditions (2001)

15. R.G. Smirnov, Technologization of politics (2005)

16. A. Touraine, A return of the actor, Essay on sociology (1998)

17. E.L. Fedotova, Information technologies in science and education (2019) 
18. J.L. Tsaurkubule, Informatization and management technologies, 2, 443 (2011)

19. NMC Horizon Report: Higher education, https://library.educause.edu 